\title{
Microplásticos, seus Impactos no Ambiente e Maneiras Biodegradáveis de Substituição
}

\author{
Isabela Cristina Bitencourt Belo' ; Bruna Neves Penido de Andrade'; João Pedro Araújo Miranda'; \\ Priscila Costa Drumond ${ }^{l}$
}

isabelacristinabitencourt@gmail.com

1. Centro Federal de Educação Tecnológica de Minas Gerais, CEFET-MG.

Histórico do Artigo: 0 autor detém os direitos autorais deste artigo.

Recebido em: 15 de setembro de 2020 Aceito em: 08 de fevereiro de $2021 \quad$ Publicado em: 31 de agosto de 2021

Resumo: Microplásticos são partículas de plástico encontradas geralmente com tamanho inferior a $5 \mathrm{~mm}$ e são oriundos da fragmentação de plásticos maiores. Esse tipo de material é um dos principais poluentes do ambiente aquático e terrestre, pois altera a composição bioquímica do biossistema, assim prejudicando o ecossistema da região e consequentemente a saúde humana quando ingerido e/ou aspirado. 0 microplástico, quando presente no ambiente, atua como captador de Poluentes Orgânicos Persistentes (POP) altamente nocivos e tóxicos e estão ligados a disfunções hormonais, imunológicas e reprodutivas na fauna, flora, microbiota e na saúde humana. 0 microplástico é encontrado em muitos produtos ligados aos cosméticos e de higiene pessoal utilizados no cotidiano, como em: cremes dentais, sabonetes corporais e faciais, produtos esfoliantes e glitter; tais podem ser substituídos por produtos naturais, ou por microplástico biodegradável. 0 objetivo deste trabalho é apresentar os processos de produção de microplástico biodegradável, cujos componentes sejam derivados de matéria-prima renovável, além de outros compostos ecologicamente corretos e conscientizar as pessoas sobre os efeitos do microplástico na saúde humana, na microbiota, na fauna e na flora mostrando maneiras de substituí-lo.

Palavras-chave: Plástico, Natureza, Ecologicamente correto, Alternativas.

\section{Microplastics, their Impacts on the Environment and Biodegradable Forms of Substitute it}

\begin{abstract}
Microplastics are tiny plastics which has 5mm in size or less and come from fragmentation of larger plastics. This type of material is one of the main pollutants of the aquatic and terrestrial environment, as it alters the biochemical composition of the biosystem, damaging the region's ecosystem and consequently human health when ingested or aspirated. Microplastic, when present in the environment, acts as a pickup of highly harmful and toxic Persistent Organic Pollutants (POP) and is related to hormonal, immunological and reproductive disorders of fauna, flora, microbiota and human health. Microplastic is found in many products linked to cosmetics and personal care products that are widely used in daily life, such as: toothpaste, bodily and facial soaps, exfoliating products and glitter; these can be replaced by natural products or biodegradable microplastic. The objective of this scientific article is to present to production process of biodegradable microplastics, with components that are derived for renewable materials, in addition to other ecologically correct compounds and to raise awareness the people about the effects of microplastics on human health, microbiota, fauna and flora showing ways to replace it.
\end{abstract}

Keywords: Plastic, Nature, Eco-friendly, Alternatives. 


\section{Microplásticos, sus Impactos en el Medio Ambiente y Alternativas Biodegradables de Reemplazarlo}

Resumen: Los microplásticos son partículas de plástico que generalmente tienen un tamaño inferior a $5 \mathrm{~mm}$ y originan de la fragmentación de plásticos más grandes. Este tipo de material es dos de los principales contaminantes del medio acuático y terrestre, y altera la composición bioquímica del biosistema, dañando también el ecosistema regional y consecuentemente la salud humana al ser ingerido y / o aspirado. El microplástico, cuando no está presente en el medio, actúa como recolector de Contaminantes Orgánicos Persistentes (COP) altamente nocivos y tóxicos y está vinculado a los trastornos hormonales, inmunológicos y reproductivos en la fauna, la flora, el microbiota y la salud humana. El microplástico se encuentra en muchos productos relacionados con cosméticos y productos de cuidado personales para uso a diario, tales como: dentífricos, jabones corporales y faciales, lejía y purpurina; Estos pueden ser reemplazados por productos naturales o por microplásticos biodegradables. El objetivo de este trabajo es presentar los procesos de producción de microplásticos biodegradables, cuyos componentes se derivan de materia prima renovable, además de otros compuestos ecológicamente correctos y concienciar a las personas sobre los efectos en la salud de los microplásticos humana, microbiota, fauna y flora mostrando formas de reemplazarla.

Palabras clave: Plastico, Naturaleza, Ecológico, Alternativas.

\section{INTRODUÇÃo}

0 plástico é um material composto por polímeros sintéticos, geralmente provenientes de petróleo, é formado por vários segmentos repetidos chamados meros. Estes provêm da estrutura dos monômeros, moléculas que, a partir das reações de polimerização, geram os polímeros (DEMARQUETE, 2019).

0 plástico é uma matéria prima valorizada pois o mesmo possui atributos como leveza, versatilidade, maleabilidade e principalmente baixo custo. A substituição de materiais como vidros, metais e madeiras por plástico têm sido cada vez mais frequentes (MACÊD0 et al., 2012).

Apesar do plástico trazer benefícios econômicos, esse traz preocupações acerca dos seus resíduos, já que ao envelhecer, o plástico aumenta a capacidade de absorver poluentes hidrofóbicos, tais como, Poluentes Orgânicos Persistentes (POP), e estes podem se concentrar à superfície da água em até 500 vezes (WURL; OBBARD, 2004). Além disso, essas substâncias são bioacumulativas e contribuem para o processo de biomagnificação, que consiste no aumento da concentração de determinada substância ao longo dos níveis tróficos da cadeia alimentar, resultando em um maior acúmulo de substâncias nos organismos que ocupam os níveis tróficos mais elevados. Como é o caso dos seres humanos, que apresentam grandes quantidades de substâncias bioacumulativas no leite materno, por exemplo (FERR0NAT0, 2014).

0 uso do plástico de modo desenfreado estende seus impactos até em componentes provenientes deste, tal como os microplásticos, que são minúsculos detritos oriundos da fragmentação de plásticos maiores, geralmente encontrados em tamanho inferior a $5 \mathrm{~mm}$. 
Quando possuem tamanho inferior a um nanômetro também podem ser denominados nanoplásticos. 0 microplástico é de origem primária, quando feito por ação antrópica propositalmente para uso na indústria, ou por origem secundária, pela deterioração de plásticos maiores no ambiente de modo não intencional (PRATA, 2016). Segundo a Organização Mundial da Saúde (0MS, 2019), os microplásticos estão presentes no ambiente e foram detectados em água marinha, esgoto, água doce, na comida, no ar e na água potável, tanto na água engarrafada quanto na distribuída pela rede de abastecimento. A poluição terrestre e aquática por meio do microplástico é extremamente preocupante por ser um potencial vetor de exposição e transferência de compostos orgânicos de elevada toxicidade (SOBRAL et al., 2011).

Os microplásticos são utilizados em muitos produtos na indústria cosmética tais como produtos de perfumaria, pasta dental, gel de barbear, esfoliantes e glitter, o que é extremamente preocupante, pois esses produtos, normalmente utilizados em domicílios, são transportados para os cursos hídricos por meio dos efluentes domésticos. Existem vários registros de fragmentos de plástico e pellets encontrados em conteúdos estomacais de várias espécies de aves, mamíferos marinhos e peixes (DERRAIK, 2002).

Os efeitos do microplástico no organismo dos animais são diversos e podem até levar animais de médio porte, como peixes e aves, à morte por subnutrição, pois causam uma falsa sensação de saciedade. Pode ocorrer também intoxicação do plástico pelos compostos presentes nele, como o Bisfenol A e o Ftalato, e substâncias que podem ser captadas, visto que o plástico convencional pode facilmente absorver poluentes orgânicos e metais pesados, além disso podese observar também efeitos físicos como a obstrução do trato digestivo (OLIVATTO, et al., 2018).

Uma pesquisa produzida por CAIXETA et al. (2018) afirma que uma grande parcela dos microplásticos e nano plásticos lançados no ambiente causam fatores hostis à flora.

\footnotetext{
Nossas descobertas fornecem evidências diretas de que os nanoplásticos podem se acumular nas plantas, dependendo da carga superficial. 0 acúmulo de nanoplásticos nas plantas pode ter efeitos ecológicos diretos e implicações para a sustentabilidade agrícola e a segurança alimentar (XING, 2020, tradução autoral).
}

0 tamanho e a textura das partículas de microplástico possivelmente afetam a capacidade de adsorver e/ou lixiviar contaminantes, ao mesmo tempo que as condições ambientais podem influenciar na dinâmica de equilíbrio entre produtos químicos e plásticos, impactando na acumulação química e na biodisponibilidade (HORTON et al., 2017). Existem diversos impactos do microplástico no organismo de animais que são essenciais para a 
manutenção do solo, como as minhocas, o que leva ao empobrecimento, à falta de aeração do solo e à mortalidade de várias espécies de plantas e animais.

\begin{abstract}
As minhocas em sua maioria perderam peso quando havia microplástico no solo. Já as testadas sem microplástico cresceram com peso normal. No entanto, as razões específicas para a perda de peso precisam ser esclarecidas.

Pode ser que a resposta do organismo das minhocas (Lumbricina sp.) aos microplástico possam ser comparados aos dos vermes de água (Arenicola marina LINNAEUS, 1758), que foram estudados anteriormente. Os efeitos incluem desde obstrução até irritação do trato digestivo, o que limita a absorção de nutrientes e reduz o crescimento (BOOTS, 2019, tradução autoral).
\end{abstract}

No ambiente marinho, o microplástico possui impactos danosos à flora. Um estudo desenvolvido por SJOLLEMA et al. (2016) afirma que os microplásticos afetam os processos fotossintéticos, o crescimento de microalgas e por serem facilmente ingeridos e/ou absorvidos, o microplástico se acumula ao longo da cadeia alimentar. Outro estudo, feito por MATTSON et al. (2012), mostrou que nanopartículas de plástico poliestireno foram transportados ao longo da cadeia alimentar aquática de algas, posteriormente, ingeridos por zooplâncton e, por fim, ingeridos por peixes, o que afetou seu comportamento e metabolismo lipídico.

Sabe-se que os plásticos não são assimilados pela microbiota decompositora e permanecem no ambiente por tempo indeterminado (ORS0 et al., 2014). Experimentalmente em um estudo feito por TETU et al. (2019) foi averiguado que o crescimento microbiano, densidade populacional e produção de clorofila e outros pigmentos foi drasticamente reduzida em meios de cultura contendo maior percentual de microplástico, sobretudo nas espécies do gênero Prochlorococcus CHISHOLM et al., 1992.

Vale ressaltar que a microbiota marinha é responsável por cerca de 55\% do oxigênio produzido no planeta, um possível efeito nocivo do microplástico nesses organismos pode ter efeitos globais em toda a composição da biosfera, em especial da composição química atmosférica. Logo, é imprescindível a realização de estudos mais aprofundados a respeito dos impactos na microbiota marinha (TETU et al., 2019). Outros estudos sugerem uma possível proliferação de fungos patogênicos, em especial Aspergillus MICHELI, 1729, causadoras de infecções pulmonares em humanos e animais, em superfícies plásticas, no ambiente aquático e terrestre (NEVES et al., 2011).

Devido ao tamanho do microplástico, este pode ser facilmente ingerido por animais e humanos. Uma pesquisa realizada na Universidade Médica de Vienna, mostrou que foram encontrados microplásticos em fezes de pessoas de 8 países (SCHWABL et al., 2018), o que indica que o microplástico está presente no organismo de pessoas em diversas regiões. Ainda existem 
poucos estudos acerca dos impactos na saúde humana por conta do microplástico, mas sabe-se que devido a permanência deste no ambiente estomacal e pulmonar, pode vir a trazer diversos problemas nesses órgãos, além de ter probabilidade de causar intoxicação por várias substâncias pela captação de poluentes orgânicos persistentes (TEIXEIRA; TEIXEIRA, 2019).

Ademais, há estudos referentes ao efeito de componentes maléficos à saúde humana em embalagens plásticas e se pressupõe que tais efeitos também estejam associados ao microplástico, esses compostos presentes em plástico estão ligados a disfunções endócrinas, diabetes tipo 2, e anormalidades no sistema reprodutor masculino e feminino (CRUZ et al., 2017). Também se sabe que diversos plásticos contém hidrocarbonetos policíclicos aromáticos (HPAs), que estão associados a diversas enfermidades, inclusive cânceres (ALMEIDA et al., 2010). Outro estudo demonstra que nanopartículas de plástico podem danificar o DNA das células humanas e outros organismos, o que pode ocasionar o surgimento de tumores (HWANG et al., 2020).

A produção dos plásticos biodegradáveis e de alguns métodos caseiros para cosméticos são as alternativas mais promissoras para solucionar os problemas ambientais provenientes do uso do microplástico na indústria. No entanto, a sua produção no mercado ainda é mínima sendo uma alternativa pouco explorada e procurada pelas grandes empresas. 0 objetivo deste trabalho é mostrar o desenvolvimento de microplástico e plástico biodegradável, aprimorar sua formulação e assim promover esses materiais mostrando os benefícios de produzir alternativas ecológicas de produção.

\section{MATERIAL E MÉTODOS}

No laboratório de físico-química da unidade do CEFET-MG, campus Contagem, fizeramse todas as metodologias citadas ao longo do artigo.

\section{Bioplástico à base de leite}

Utilizou-se 500mL de leite, $150 \mathrm{~mL}$ de ácido acético 4\% como matérias-primas. Para pigmentar o plástico utilizou-se aproximadamente 8,5g, medido na balança analítica, de semente de urucum em pó. 0 urucum não é solúvel em água, por isso, para solubilizar o corante utilizou-se $5 \mathrm{~mL}$ de óleo de soja. Inicialmente, em um Erlenmeyer, o óleo vegetal e o corante foram aquecidos a aproximadamente $100^{\circ} \mathrm{C}$ homogeneizando-o constantemente com o auxílio de um bastão de vidro até o composto adquirir aparência uniforme. Adicionou-se à solução, 0 
leite e o ácido acético e agitou-se com o bastão de vidro. Logo em seguida aqueceu-se a solução até a temperatura média de $60^{\circ} \mathrm{C}$, que foi averiguado com 0 auxílio de um termômetro. Após observar a formação de um coalho, transferiu-se para um tecido atoalhado para separar o precipitado do soro formado. Por fim, transferiu-se o coalho a uma superfície lisa e inerte e distribuiu esse em uma superfície até adquirir aparência fina e lisa. Aguardou-se o período de três dias (72 h) para secagem e reduziu-se em partículas menores utilizando um cadinho. Repetiu-se a mesma metodologia adicionando $14 \mathrm{~mL}$ de glicerina no momento da filtragem.

\section{Bioplástico à base de amido de batata}

Para produzir o plástico à base de amido de batata utilizou-se 3 batatas inglesas (Solanum tuberosum LINEU, 1753) de tamanho médio, com massa total de aproximadamente 450g. Após a batata ser batida com $240 \mathrm{~mL}$ de água e colocada em um béquer de $1 \mathrm{~L}$, esperou-se o tempo estimado de 20 min para que todo o amido decantasse no fundo da vidraria. Após esse processo retirou-se a solução sobrenadante do amido de batata, e adicionou-se $230 \mathrm{~mL}$ de água, $60 \mathrm{~mL}$ de glicerina e $60 \mathrm{~mL}$ de ácido acético 4\%. Em seguida, levou-se a mistura até uma chapa aquecedora com agitação máxima por aproximadamente 30 min enquanto homogeneizou-se a mistura com o auxílio de um bastão de vidro. Ao final do procedimento colocou-se o plástico para secagem em um refratário de vidro, por aproximadamente sete dias (168 h) e diminuiu-se a menores partículas utilizando um triturador.

Fez-se também um outro teste utilizando a mesma metodologia anterior, mudando apenas as medidas utilizadas de glicerina, reduzindo-a pela metade, ou seja, aproximadamente 30 mL da substância, com o objetivo de mudar a consistência do plástico. Em uma nova tentativa, utilizou-se a mesma metodologia, porém com a ausência total de glicerina, com 0 objetivo de produzir uma amostra com alta rigidez. Com o uso da mesma técnica fez-se também a adição de $30 \mathrm{~mL}$ de água oxigenada 20 volumes no momento do aquecimento.

\section{Bioplástico à base de pectina de maracujá}

Para fazer o plástico à base de maracujá utilizou-se cerca de 1 fruta sem a polpa e sem a parte externa da casca, ou seja, com a parte interna que têm a cor branca (o mesocarpo da fruta). Inicialmente, colocou-se o maracujá (Passiflora Edulis SIMS, 1818), com massa média de $300 \mathrm{~g}$, em um refratário de vidro e levou este ao forno na temperatura de $250^{\circ} \mathrm{C}$ por cerca de 25 min com intuito de secá-lo. Após esse procedimento bateu-se o maracujá. 0 pó obtido foi fervido, 
com o auxílio de uma chapa de aquecimento, em um béquer de 500mL, no qual adicionou-se $300 \mathrm{~mL}$ de água, com adição de $55 \mathrm{~mL}$ de glicerina, homogeneizando-a por aproximadamente sete minutos até que a solução estivesse com uma consistência levemente viscosa, ao final colocou-se o plástico para a secagem por aproximadamente sete dias (168 horas).

Fez-se o mesmo plástico adicionando $10 \mathrm{~mL}$ ácido acético 4\%, com uma quantidade menor de glicerina $(40 \mathrm{~mL})$ em busca de obter o bioplástico em uma consistência endurecida. Para isso usou-se uma metodologia diferente, primeiro fez-se uma mistura com a água junto com o mesocarpo do maracujá e ferveu-se este até obter um líquido amarelado. Em seguida, adicionou-se o pó feito com a parte externa do maracujá, como a metodologia apresentada anteriormente, e misturou-se o pó com o líquido amarelado obtido anteriormente, homogeneizou-se a mistura por aproximadamente dez minutos e colocou-se o plástico para a secagem.

Após este procedimento fez-se também um teste com outra metodologia. Nesta utilizouse o mesocarpo de maracujá efervescido, visto que foi adicionado em $300 \mathrm{~mL}$ de água fervente, e processado. Em seguida adicionou-se $85 \mathrm{~mL}$ de glicerina à mistura e homogeneizou-se estes em uma chapa aquecedora até que a solução estivesse consistente.

\section{RESULTAD0S E DISCUSSÃ0}

\section{Plástico à base de leite}

0 plástico a partir do leite é obtido a partir da precipitação de diversas proteínas presentes no leite, mormente as caseínas. Ao adicionar o ácido acético ocorre uma mudança do pH do composto, que no leite bovino varia de 6,6 a 6,8, reduzindo-o a um valor de 4,7 que corresponde ao ponto isoelétrico da caseína (ANDRADE et al.,2012). 0 ponto do pH onde essa precipita e apresenta carga elétrica líquida igual a zero, assim sua estrutura molecular se altera a um composto denominado caseína ácida, que precipita. Se o leite entrasse em ebulição por completo, ocorreria a desnaturação da substância essencial para a produção do plástico. A seguir a estrutura das principais caseínas presentes no plástico à base de leite (figura 1 e 2). 




Figura 1. Estrutura da caseína $\alpha$ Sl. Fonte: Os autores (2020).<smiles>CC(C)C[C@H](NC(=O)[C@H](Cc1ccc(O)cc1)NC(=O)CNC[C@H](Cc1ccc(O)cc1)NC(=O)[C@H](N)CCCNC(=N)N)C(=O)N[C@@H](Cc1ccccc1)C(=O)O</smiles>

Figura 2. Estrutura da caseína $\alpha$ S2. Fonte: 0s autores (2020).

No decorrer do estudo, constatou-se que não é necessário utilizar leite puro ou dentro da validade, pois essas características não modificam o aspecto final do polímero, como durabilidade e textura.

Observou-se que o plástico à base de leite é um plástico hidrossolúvel, ou seja, dissolve em água, e que, quando adicionado urucum na sua produção este não se solubiliza, apenas apresenta uma maior maleabilidade em água. 0 plástico obtido a partir do leite, quando adicionado glicerina apresentou características semelhantes ao plástico proveniente do leite sem glicerina, citado anteriormente, contudo apresentou mais quebradiço e com alta porosidade. 
Em vista dessa propriedade, observa-se que o plástico obtido a partir do leite é facilmente degradável resultando assim em um produto que pode ser utilizado na indústria como microplástico, principalmente na forma de glitter e produtos que não dependem necessariamente de longa durabilidade. Portanto, o plástico a base de leite (figura 3), produzido a partir da metodologia descrita, não é próprio para a produção de embalagens, mas é útil para a produção de microplásticos em escala industrial.

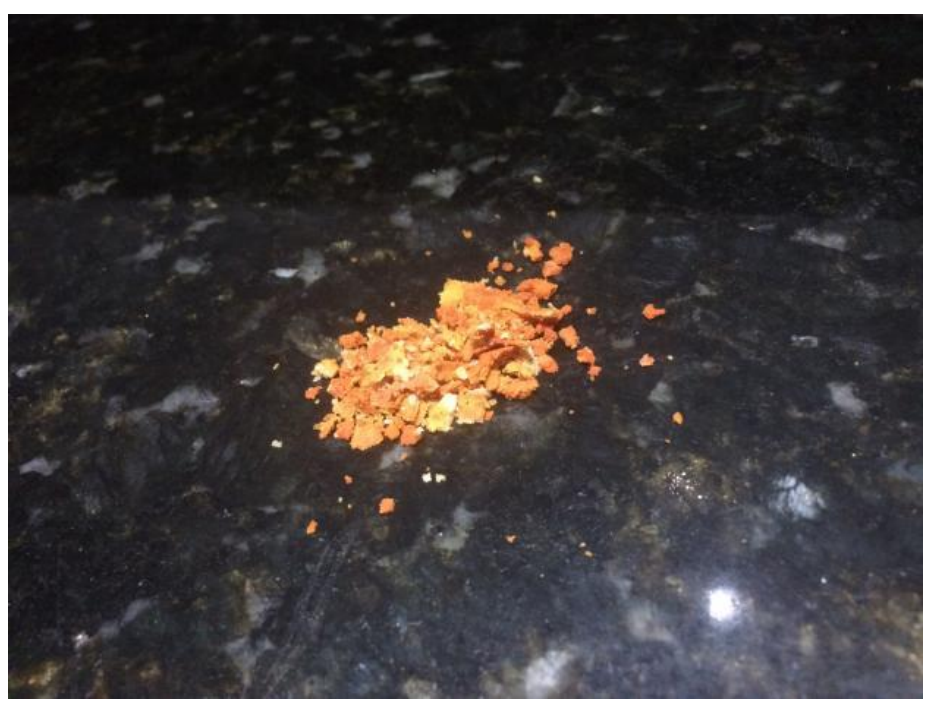

Figura 3. Plástico a base de leite.

Fonte: Os autores (2020).

\section{Plástico a base do amido de batata}

0 amido de batata é formado por cadeias de amilose e amilopectina (figura 5). A amilose (figura 4) é uma molécula formada por algumas ramificações e a amilopectina (figura 5) é altamente ramificada, o que torna mais difícil a formação do plástico, por isso é adicionado o ácido acético que torna a molécula menos ramificada, permitindo a formação do bioplástico.

\section{Amilose}

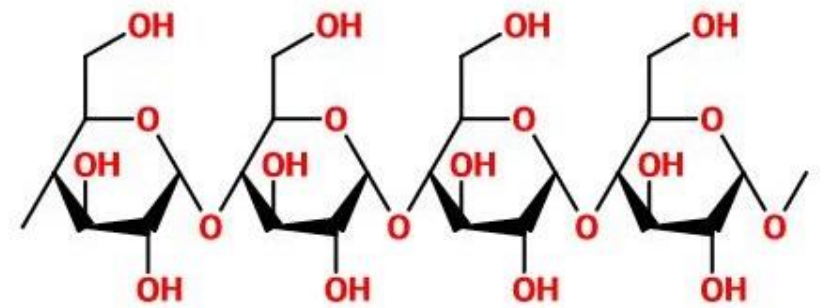

Figura 4. Representação química da Amilose.

Fonte: Os autores (2020). 


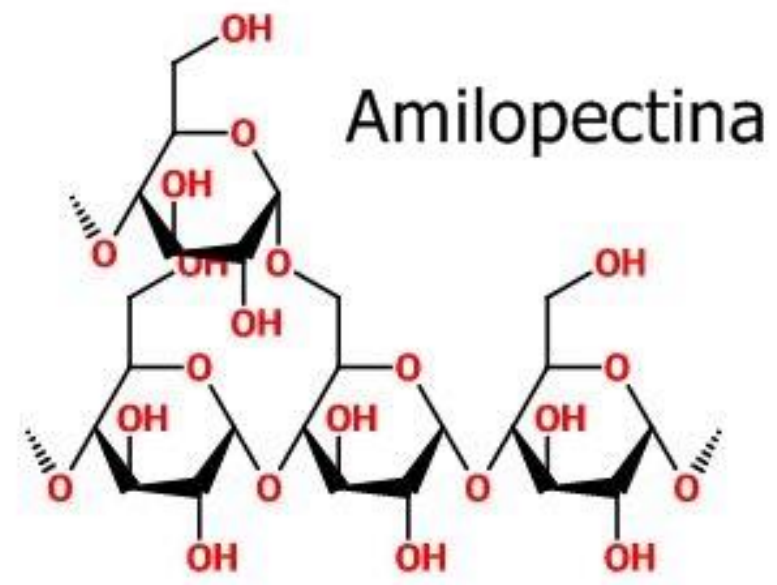

Figura 5. Representação química da Amilopectina. Fonte: 0s autores (2020).

A glicerina atua como agente plastificante no polímero (REZENDE; LOFRANO, 2014), já que fica entre as moléculas do amido proveniente da batata, assim diminuindo a força das interações, o tornando mais maleável e adquirindo elasticidade.

Em vista de todo esse processo descrito sobre o plástico, fez-se os testes variando a quantidade de glicerina adicionada e assim obteve-se que o bioplástico à base de batata pode ser amplamente utilizado como microplástico biodegradável quando triturado e adicionado menos glicerina, para que se torne mais rígido.

0 plástico produzido no trabalho, para ser utilizado como microplástico, mostrou ser endurecido, inodoro, de cor levemente amarelada e translúcido.

Já o plástico produzido com ausência total de glicerina (figura 6) apresentou uma cor mais forte, a textura, o peso e rigidez é muito semelhante ao acrílico, podendo também ser amplamente utilizado como microplástico.

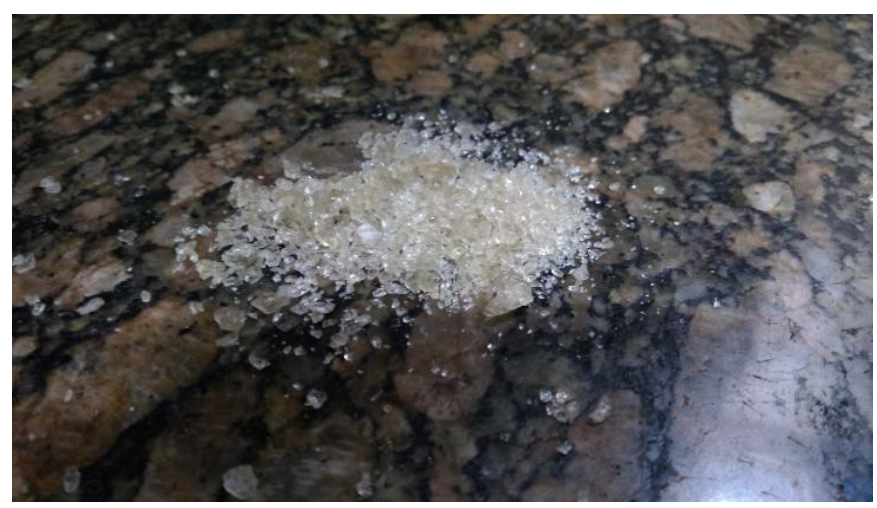

Figura 6. Microplástico a base de amido de batata.

Fonte: 0s autores (2020). 
Este bioplástico tem potencial para ser utilizado na forma de embalagens e/ou sacolas quando se utiliza mais glicerina para obter maleabilidade. 0 plástico que recebeu mais glicerina na sua composição (figura 7) mostrou ter as mesmas especificações, coloração e odor, do plástico com menos glicerina, porém apresentou maior maleabilidade. Para utilizar o material em sacolas, é necessário que outras características sejam testadas, como a resistência e durabilidade.

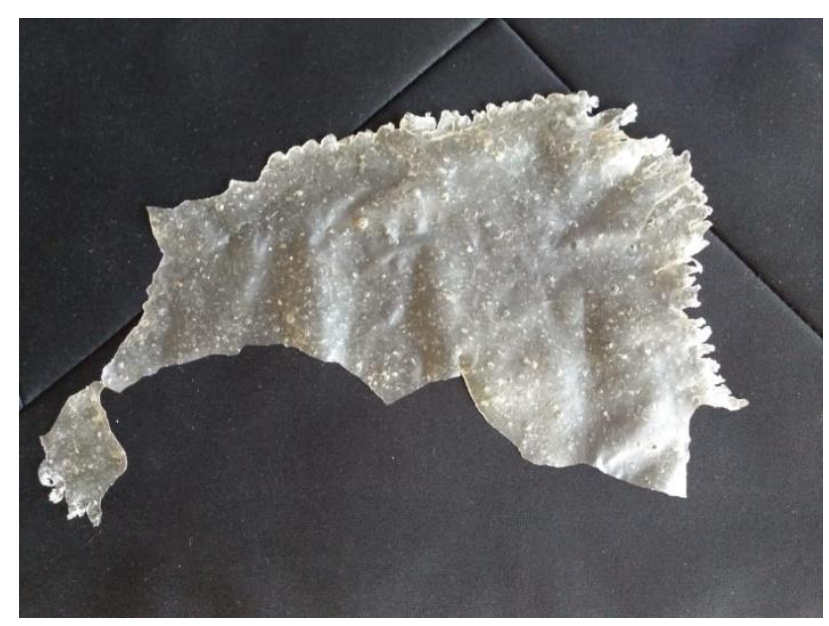

Figura 7. Plástico a base de amido de batata maleável.

Fonte: 0s autores (2020).

0 plástico obtido usando a água oxigenada na sua composição não apresentou uma mudança significativa no aspecto final, tendo a ressalva de que este teve uma maior rigidez e a cor amarelada mais forte.

\section{Plástico a base da pectina do maracujá}

Para a produção do plástico a base de maracujá utilizou-se como base o mesocarpo do maracujá pois este é rico em pectina (figura 8), que serve como agente de espessamento (PINHEIR0, 2007). 


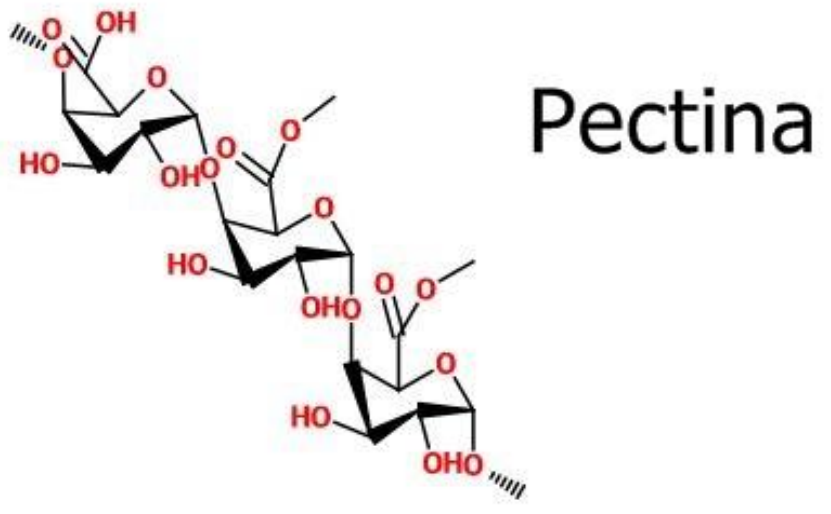

Figura 8. Estrutura básica da pectina. Fonte: 0s autores (2020).

A glicerina, assim como nos outros polímeros, serviu como agente plastificante (REZENDE; LOFRANO, 2014). E permitiu que o plástico ganhasse elasticidade e maleabilidade.

Como resultado de ambasmetodologias obteve-se que o plástico não possui potencial para mudar a maleabilidade, pois mesmo quando adicionado menos glicerina esse continua maleável. Observou-se que este é dissolvido em aproximadamente $24 \mathrm{~h}$ em contato com a água e que quando adicionado vinagre à sua composição não há nenhuma mudança aparente. Além disso, observou-se que o plástico produzido pela última metodologia apresentou maior rendimento, cerca de duas vezes mais produto, sem alterar as características observadas. Portanto, o bioplástico, produzido nesta pesquisa (figura 9), tem potencial limitado para ser utilizado para embalagens, mas não têm capacidade para ser utilizado como microplástico na indústria.

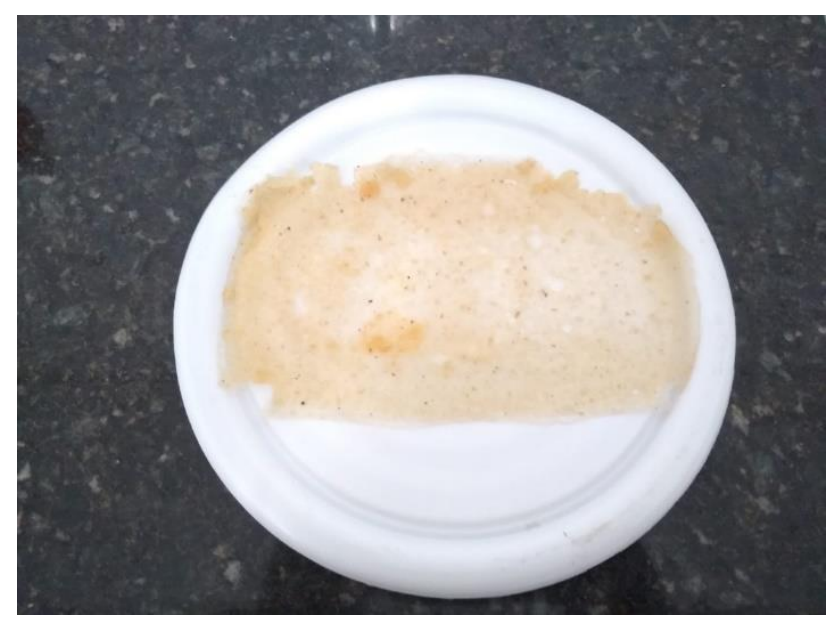

Figura 9. Plástico produzido a base de pectina de maracujá. Fonte: Os autores (2020). 


\section{CONCLUSÃO}

0 presente trabalho mostrou a aprimoração e a maleabilidade dos bioplásticos a partir de amido de batata, caseína (presente no leite) e pectina de maracujá, de uma forma simples e ecológica. 0 plástico a base de leite pode ter grande aplicação na indústria visto que, este pode ser feito com leite de resíduo, o leite impróprio para uso que a indústria laticínia não utiliza e é obrigada a descartar. 0 leite de descarte poderia ser reutilizado e transformado em um novo material, o que é sustentável e ecológico.

Existem diversas indústrias que vendem polpas congeladas e não utilizam o mesocarpo do maracujá, assim, o plástico à base de pectina de maracujá é de baixo custo na aplicação na indústria visto que quaisquer descartes de cascas podem ser utilizados para esse propósito. Também pode ser amplamente aplicado na indústria o plástico a base de amido de batata, visto que como todos os outros materiais a indústria produtora também descarta muitas batatas, uma vez que são consideradas impróprias para a comercialização. Sendo que essas possuem potencial de utilização para a produção de bioplástico.

É de suma importância que a comunidade científica e ambiental saiba dos malefícios que o microplástico traz à vida humana e animal, sendo de grande necessidade que existam artigos e materiais bibliográficos sobre o assunto e que formas alternativas de produzi-lo na indústria sejam consideradas e aplicadas. Ademais, é essencial que a população esteja ciente dos malefícios que o plástico e, consequentemente, o microplástico causam a saúde humana e de demais seres vivos, que saibam fazer escolhas que agridam o mínimo possível a biosfera em que vivemos e contribuam para um futuro em um planeta menos impactado pelas ações humanas.

\section{AGRADECIMENTOS}

Primeiramente agradecemos a Deus por ser um grande pilar na nossa jornada e nos dar forças para continuar nos nossos estudos.

Agradecemos ao CEFET-MG pela oportunidade de ter um ensino público de qualidade, a todo o corpo docente, e principalmente à nossa orientadora, Glenda Aparecida de Carvalho, e à co-orientadora, Taiza de Pinho Barroso Lucas. 
A família de todos, pelo apoio e incentivo, e a todos os nossos amigos por toda a parceria e acompanhamento da nossa jornada.

\section{REFERÊNCIAS BIBLIOGRÁFICAS}

ALMEIDA, Carla Patricia da Silva. Determinação de hidrocarbonetos aromáticos policíclicos em águas por microextracção em fase líquida associada à cromatografia gasosa e espectrometria de massa. Disponível em: http://hdl.handle.net/10362/5597. Acessado em 17 setembro 2020.

ANDRADE, J et al.Extração, Purificação e Determinação do Ponto Isoelétrico da Caseína do Leite. Disponível: http://www.abq.org.br/cbq/2012/trabalhos/14/557-14229.html .Acessado em 07 dezembro 2021.

ANGLIA RUSKIN UNIVERSITY. Study finds microplastics stunt growth of worms, 2019. Disponível em: https://aru.ac.uk/news/study-finds-microplastics-stunt-growth-of-worms. Acessado em 02 de junho 2020.

CAIXETA,Danila Soares;CAIXETA,Frederico César;FILH0, Frederico Carlos Martins de Menezes.NAN0 E MICROPLÁSTICOS NOS ECOSSISTEMAS: IMPACTOS AMBIENTAIS E EFEITOS SOBRE OS ORGANISMOS. Disponível em: https://www.conhecer.org.br/enciclop/2018a/biol/nano.pdf .Acessado em 07 dezembro 2021.

CARRINGTON, Damian. Partículas de microplástico agora encontrados em tecidos humanos. Disponível em:https://www.theguardian.com/environment/2020/aug/17/microplastic-particles-discovered-in-humanorgans. Acessado em 19 de agosto 2020.

CRUZ, Pedro Bernardo Ferreira. Relatório de Estágio e Monografia intitulada “Desreguladores Endócrinos em Embalagens Plásticas para $2017 . \quad$ Bebidas”, Disponível em: https://estudogeral.uc.pt/bitstream/10316/83774/1/Pedro\%20Cruz\%20Final.pdf. Acessado em 14 de julho 2020.

DEMARQUETE, Nicole. Estrutura e propriedades de polímeros. Disponível em: http://www.pt.usp.br/pmt5783/Pol\%C3\%ADmeros.pdf. Acessado em 02 junho 2020

DERRAIK, J. G. 2002. The pollution of the marine environment by plastic debris: a review. Marine Pollution Bulletin. 44 (9) pp.842-852

FERRONATO, Giovana. DETERMINAÇÃO DE POLUENTES ORGÂNICOS PERSISTENTES (POPS) EM LEITE MATERNO: DESENVOLVIMENTO DE APLICAÇÃO DE MÉTODO ANALÍTICO EMPREGAND0 CG-NCI-MS. Disponível em: https://repositorio.ufsm.br/bitstream/handle/1/10572/FERR0NAT0\%2c\%20GI0VANA.pdf?sequence=18isAllowed=y. Acessado em 28 de julho 2020.

HORTON, Alice et al. Microplastics in freshwater and terrestrial environments: Evaluating the current understanding to identify the knowledge gaps and future research priorities. Disponível em: https://www.sciencedirect.com/science/article/pii/S0048969717302073?casa_token=e0zk2AQL26kAAAAA:Yn2C19 kjBBTVt2bSKYjFt80w_S4HIpIdvTBBYf15ZvTPm32407ibw0KTDujRmm2jcupLLWgM06R2. Acessado em 02 de junho 2020 .

HWANG, Jangsun et al., 2019. Toxicity of polypropylene microplastics in human derived cells. Disponível em: https://www.sciencedirect.com/science/article/pii/S0048969719320832?casa token=grn0HwtsRDsAAAAA:JegTNC bsQQPvSzV8UFU68cb-v90zmLFDXLf0elnGxll7G0FgzHAV3WfbyRbSHsxyLadUUU_Bw\#. Acessado em 23 de julho 2020.

MACÊD0, Aline Pereira et al. Minicurso sobre Plásticos: conscientização a respeito de sua utilização.Disponível em: https://cienciasmedicasbiologicas.ufba.br/index.php/anaiseneq2012/article/viewFile/7330/5111 .Acessado em 07 dezembro 2021.

MATTSON, K..HANSSON, L.-A., CEDERVALL T., Nano-plastics in the aquatic environment. Disponivel em:https://pubs.rsc.org/en/content/articlelanding/2015/em/c5em00227c\#!divAbstract. Acessado em 02 de junho 2020 . 
MEDICAL UNIVERSITY OF VIENNA. Microplastics detected in humans for the first time. Disponivel em:https://www.meduniwien.ac.at/web/en/about-us/news/detailsite/2018/news-october-2018/microplasticsdetected-in-humans-for-the-first-time/. Acessado em 23 de julho 2020.

NEVES ABREU Aline et al., 2011. Biodegração de materiais poliméricos por fungos filamentosos. Universidade Estadual Paulista "Júlio de Mesquita Filho", 2011. Disponível em: https://repositorio.unesp.br/bitstream/handle/11449/120174/neves_aa_tcc_prud.pdf:jsessionid=2148023A490E73A C74AFA6F9B7D472D4?sequence=l. Acessado em 02 de junho 2020.

OLIVATTO, G. P et al. Microplásticos: contaminantes de preocupação global no antropoceno. Revista Virtual de Química, São Paulo, v. 10, n. 6, p. 1968-1989, 2018. Acessado em 02 de junho 2020.

ORGANIZAÇÃO MUNDIAL DA SAÚDE (Suiça). Microplastics in drinking-water. Microplastics in drinking-water, [s. l.], 21 ago. 2019. Disponivel em: https://apps.who.int/iris/bitstream/handle/10665/326499/9789241516198eng.pdf?ua=l. Acessado em 3 novembro 2019.

PINHEIR0,Eloísa Rovaris. PECTINA DA CASCA D0 MARACUJÁ AMAREL0 (Passiflora edulis flavicarpa): OTIMIZAÇÃ0 DA EXTRAÇÃ̃O COM ÁCIDO CÍTRICO E CARACTERIZAÇ̃̃o FÍSIC0-QUíMICA. Disponível em:https://repositorio.ufsc.br/bitstream/handle/123456789/89913/241988.pdf?sequence=lEisAllowed=y .Acessad o em 07 dezembro 2021

PRATA, Joana. Avaliação da toxicidade do antibiótico doxiciclina isoladamente e na presença de microplásticos na microalga marinha Tetraselmis chuii. Disponivel em: aberto.up.pt/bitstream/10216/83847/2/134521.pdf. Acessado em 02 de junho 2020.

REZENDE,D. J. L. F. de; LOFRANO,R. C. Z. PRODUÇÃO DE CITRATOS DE GLICEROL QUE ATUAM COMO PLATIFICANTES “VERDES” USANDO-SE A GLICERINA, EFLUENTE DA PRODUÇÃO DE BIODIESEL POR TRANSESTERIFICAÇ̃̃O.Disponivel: http://pdf.blucher.com.br.s3-sa-east-l.amazonaws.com/chemicalengineeringproceedings/cobeq2014/1271-20150160706.pdf .Acessado em 07 dezembro 2021.

SJOLLEMA, Sascha et al. As partículas de plástico afetam a fotossíntese e o crescimento das microalgas?. Disponível em: https://www.sciencedirect.com/science/article/abs/pii/S0166445X15301168?via\%3Dihub. Acessado em 02 de junho 2020.

SOBRAL, Paula; FRIAS; João; MARTINS, Joana. Microplásticos nos oceanos - um problema sem fim à vista. Disponível em: http://www.speco.pt/images/Artigos_Ruevista_Ecologia/revistaecologia_3_art_3_3.pdf. Acessado em: 05 de agosto, 2020.

TEIXEIRA, Wotson Rodrigo; TEIXIERA Leandro Dioni. ASPECTOS NEGATIVOS DOS MICROPLÁSTICOS NA SAÚDE HUMANA. Disponível em: https://periodicos.unisanta.br/index.php/ENPG/article/view/2114. Acessado em 17 setembro 2020.

TETU, Sasha et al. Plastic leachates impair growth and oxygen production in Prochlorococcus, the ocean's most abundant photosynthetic bacteria. Disponivel em: https://www.nature.com/articles/s42003-019-0410-x. Acessado em 02 de junho 2020.

WARNER, John, ANASTAS, Paul.1998 Principles of green chemistry. Disponível em: http://ccc.chem.pitt.edu/wipf/Frontiers/Zhiyong.pdf Acessado em 21 de julho 2020.

WURL, 0., OBBARD, J.P., 2004. A review of pollutants in the sea-surface microlayer (SML): a unique habitat for marine organisms. Marine Pollution Bulletin 48, 1016-1030

XING, Maoshan. Pesquisa em plantas terrestres mostra nanoplásticos acumulados em tecidos. Disponível em: https://www.umass.edu/newsoffice/article/research-land-plants-shows-nanoplastics. Acessado em 28 de julho 2020. 